\title{
Current Patterns in the Inner Sound (Pentland Firth) from Underway ADCP Data*
}

\author{
Lonneke Goddijn-Murphy, David K. WoOlf, And MatThew C. EAston \\ Environmental Research Institute, North Highland College, University of the Highlands and Islands, Thurso, Scotland
}

(Manuscript received 12 December 2011, in final form 7 August 2012)

\begin{abstract}
Numerous acoustic Doppler current profiler (ADCP) surveys were performed in the Inner Sound of the Pentland Firth, a channel between the Orkney Islands and the northern coast of Scotland connecting the Atlantic Ocean to the west and the North Sea to the east. The Pentland Firth has the highest tidal streams of the British Isles, and one of the highest that can be found around the globe. Here, the tidal energy industry is in its demonstration phase, but not many real current measurements are in the public domain. The authors present real current data, measured during different phases of the tidal cycle, using a vessel-mounted ADCP. The tidal changes can be rapid, and because the underway measurements take time, the apparent spatial patterns are affected by temporal variation. A method is described that estimated and corrected this temporal distortion using a hydrodynamic model. It appeared that ebb and flood streams did not fully overlap, and that the tidal streams were more complicated, turbulent, and variable than existing models suggest. The data were analyzed for characteristics pertinent to practical tidal stream energy exploitation, and two favorable sites in the Inner Sound are identified. All original current data are available from the British Oceanographic Data Centre (BODC).
\end{abstract}

\section{Introduction}

Tidal power in the British Isles has the potential to be used on an industrial scale; MacKay (2009) identifies six top locations where peak tidal flows exceed $1 \mathrm{~m} \mathrm{~s}^{-1}$. Of these locations, the Pentland Firth (Fig. 1) has by far the highest average kinetic power density (power per unit area of the sea floor), estimated at $170 \mathrm{~W} \mathrm{~m}^{-2}$ over an area of $50 \mathrm{~km}^{2}$ (MacKay 2009). These numbers would result in an average power of $\sim 8.5 \mathrm{GW}$; in comparison, Salter and Taylor (2007) presume about one-third of $53 \mathrm{GW}$ could be captured in the Pentland Firth on average. The Carbon Trust (2011) argues that the resource in the Pentland Firth Deep (water depth $>30 \mathrm{~m}$ ) is significantly reduced by practical constraints, but still makes up about $30 \%$ of all U.K. practical resources ("practical" meaning a resource that is environmentally,

\footnotetext{
* Supplemental information related to this paper is available at the Journals Online website: http://dx.doi.org/10.1175/JTECHD-11-00223.s1.

Corresponding author address: Lonneke Goddijn-Murphy, Environmental Research Institute, UHI-NHC, CfEE Building, Ormlie Road, Thurso, KW14 7EE, Scotland.

E-mail: lonneke.goddijn-murphy@thurso.uhi.ac.uk
}

economically, and practically feasible to extract). For the Pentland Firth Deep the Carbon Trust expects the

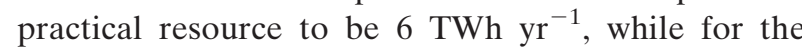
Pentland Firth Shallow (water depth $<30 \mathrm{~m}$ ) $1 \mathrm{TWh} \mathrm{yr}^{-1}$ is calculated, implying a useful average power of 0.7 and $0.1 \mathrm{GW}$ for the deep and shallow part of the Pentland Firth, respectively.

Calculations like these are based on numerical models and/or limited historical survey data because very few velocity measurements from the Pentland Firth are available in the public domain. Admiralty charts and tidal atlases are a conventional source of tidal stream velocity datasets. Admiralty chart 2162 United Kingdom Hydrographic Office (2009) shows a small number of tidal diamonds in the area, and only in the weaker flows ( $<3.1 \mathrm{kt})$. In the Admiralty Tidal Stream Atlas NP 209 (United Kingdom Hydrographic Office 1986), neap/ spring currents as strong as 4.0/9.0 kt $\left(2.1 / 4.6 \mathrm{~m} \mathrm{~s}^{-1}\right)$ are indicated for the regions north and west of the Island of Stroma, and 2.0/5.0 kt (1.0/2.6 m s$\left.~^{-1}\right)$ south of Stroma in the Inner Sound. Bryden et al. (2007) interpolated United Kingdom Hydrographic Office (2009) Admiralty chart data to create flow maps of the Pentland Firth identifying large-scale spatial and temporal variations. At the local, site-specific scale, however, this approach is ultimately restricted by the accuracy and resolution of 


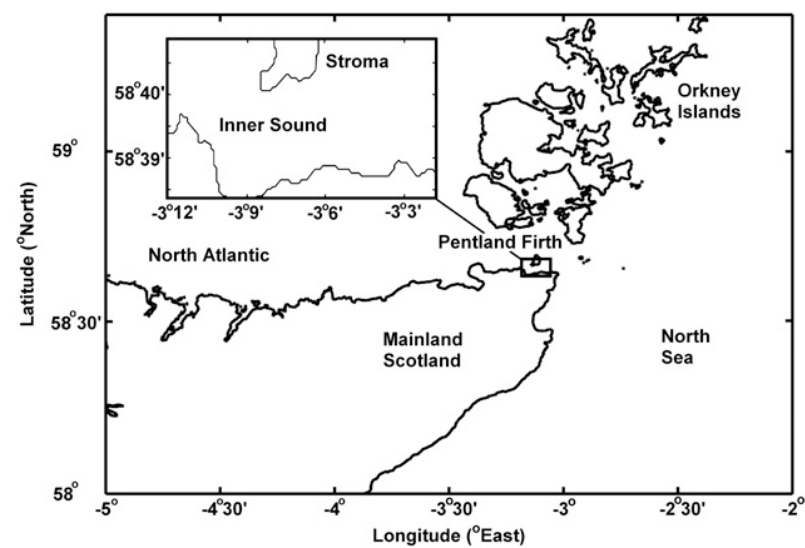

FIG. 1. Map of the north of Scotland showing the Inner Sound in the Pentland Firth, where the survey site was located.

the source data. Sankaran Iyer et al. (2009) indicate that complex tidal phenomena cannot be represented from interpolation of such sparse datasets. Requirements for direct measurements in resource assessment are highlighted by Owen and Bryden (2007), who state that historical data provide, at best, a "general approximation." In reality, the tidal streams are likely to be more complicated, turbulent, and variable than published sources suggest.

Numerical modeling has been used to provide a more comprehensive description of the tidal dynamics in the Pentland Firth. The tides in the region are primarily semidiurnal with a primary $M_{2}$ tide and secondary $S_{2}$ tide both propagating toward the east. The amplitude of the tides is approximately double on the Atlantic end compared to the North Sea end. Exceptional sea surface slopes along the Pentland Firth are related both to the amplitude difference and phase difference of the tides at each end. A three-dimensional model of the $M_{2}$ tide, applied by Davies et al. (2001), explains how a significant tidal elevation between the western and eastern side of the Pentland Firth gives rise to strong tidal currents in the region. Although the grid of their model, of $\sim 5$ - $\mathrm{km}$ resolution, is considerably finer than those used in global and shelfwide models, it cannot reproduce detailed flows in regions such as the Pentland Firth. The Proudman Oceanographic Laboratory (2007) has developed numerical tidal prediction software, known as POLPRED, which has been implemented over the U.K. continental shelf to produce tidal stream atlases (Bell and Carlin 1998). POLPRED's Orkney Model (ORKM) describes two-dimensional flows in the Pentland Firth, on a $1 / 120^{\circ}$ latitude by $1 / 60^{\circ}$ longitude grid (approximately a $\sim 1$-km resolution; Fig. 2). ORKM predicts the general features of flow in the Pentland Firth but necessarily cannot describe features of less than a 1-km scale. It is immediately obvious from underway surveys (Goddijn-Murphy

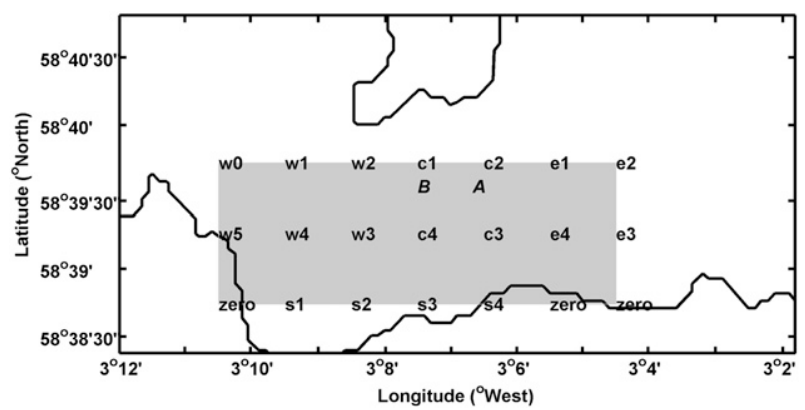

FIG. 2. POLPRED grid points that were used in the timecorrection method (see Table 2). All surveys were performed inside the gray area. Sites A and B indicate most promising locations for tidal energy devices.

and Woolf 2009) that flow varies greatly on smaller scales. In this paper we describe these observations and explain a method of inferring information from a combination of the observations and the low-resolution model.

Standard procedures on field data collection for tidal resource characterization have been proposed by Legrand (2009) and Venugopal et al. (2011). The latter mention four main drivers for measurements in wave and tidal resource characterization: energy resource, engineering design, marine operations, and data for numerical model validation and calibration. Together, these applications require rather detailed characteristics that can only be acquired reliably by extensive measurement programs. In the case of tidal characteristics, direct current measurements are essential and acoustic Doppler current profilers (ADCPs) are often the instrument of choice. An ADCP can work in different setups. A bottom-mounted ADCP is often deployed for measuring temporal variations, while a vessel-mounted ADCP can measure spatial variations. A stationary ADCP is typically left at the sea bottom for between 15 days and 3 months, and installing more than one is highly recommended by Legrand (2009). However, deployment and recovery of ADCPs in the extreme current and wave climate of the Pentland Firth has proven to be extremely difficult. In this environment, underway ADCP surveys may offer a more practical alternative. Individual ADCP transects should be shorter than 10 min to avoid significant changes in the flow conditions during the survey (Legrand 2009; Venugopal et al. 2011), but this greatly limits the extent of surveys. We developed an alternative approach by performing underway ADCP surveys of several hours and using the ORKM predictions during postprocessing to correct for changes of the tide; the results were "snapshots" of the tidal patterns. Using our data, we indicated the most promising locations for deploying tidal stream turbines with respect to a number of turbine-relevant metrics. 
TABLE 1. Summary of the survey conditions. Column "\# tracks" shows $a / b$, where $a$ equals the number of transects, and $b$ equals the number of times the survey area is covered. Area: "Large" indicates longitudes between $3^{\circ} 10^{\prime}$ and $3^{\circ} 4^{\prime} \mathrm{W}$, and latitudes between $58^{\circ} 39^{\prime}$ and $58^{\circ} 40^{\prime} \mathrm{N}$, and "Small" indicates longitudes between $3^{\circ} 8^{\prime} 30^{\prime \prime}$ and $3^{\circ} 5^{\prime} 30^{\prime \prime} \mathrm{W}$, and latitudes between $58^{\circ} 39^{\prime}$ and $58^{\circ} 39^{\prime} 45^{\prime \prime} \mathrm{N}$.

\begin{tabular}{lcllcc}
\hline \multicolumn{1}{c}{ Date } & Time (UTC) & \multicolumn{2}{c}{ Tidal stage } & \# tracks & Area \\
\hline 2 Apr 2009 & $1126-1503$ & Neap & Flood & $3 / 1$ & Large \\
7 Apr 2009 & $1016-1210$ & Medium & Ebb & $3 / 1$ & Large \\
8 Apr 2009 & $1212-1451$ & Medium & Ebb & $5 / 1$ & Large \\
15 Apr 2009 & $0913-1202$ & Neap & Flood & $4 / 1$ & Large \\
29 Apr 2009 & $1235-1453$ & Medium & Flood-ebb & $4 / 4$ & Small \\
4 Jun 2009 & $1256-1607$ & Neap & Ebb-flood & $4 / 4$ & Small \\
1 Jul 2009 & $1037-1349$ & Medium & Ebb-flood & $5 / 5$ & Small \\
23 Jul 2009 & $1023-1253$ & Spring & Flood-ebb & $3 / 3$ & Small \\
29 Oct 2009 & $1102-1257$ & Neap & Ebb & $2 / 2$ & Small \\
\hline
\end{tabular}

Calculating the tidal power resource is not the aim of this paper; for methodology related to that we refer the reader to Garrett and Cummins (2005) or Vennell (2011).

\section{Methodology}

\section{a. Survey conditions}

\section{1) LOCATION}

The Pentland Firth is a $\sim 20-\mathrm{km}$-wide channel between the northeastern tip of Scotland and the Orkney Islands, connecting the North Atlantic to the west with the North Sea to the east (Fig. 1). Numerous surveys were performed in the Inner Sound, a subsidiary channel separating the Island of Stroma and the Scottish mainland, with a width of over $3 \mathrm{~km}$. In the Inner Sound, the water depth is $35 \mathrm{~m}$ at maximum. The initial survey tracks covered longitudes between $3^{\circ} 10^{\prime}$ and $3^{\circ} 4^{\prime} \mathrm{W}$, and latitudes between $58^{\circ} 39^{\prime}$ and $58^{\circ} 40^{\prime} \mathrm{N}$, an area of about $6 \mathrm{~km}$ by $2 \mathrm{~km}$. The transects were laterally spaced by $\sim 300 \mathrm{~m}$. After analyzing results from four surveys, each during different tidal stages, the study area was refined to between $3^{\circ} 8^{\prime} 30^{\prime \prime}$ and $3^{\circ} 5^{\prime} 30^{\prime \prime} \mathrm{W}$ longitude and $58^{\circ} 39^{\prime}$ and $58^{\circ} 39^{\prime} 45^{\prime \prime} \mathrm{N}$ latitude (about $3 \mathrm{~km} \times 1.5 \mathrm{~km}$ ). This halved the area for the subsequent five surveys, enabling tracks that covered the same ground more than once during a survey. In total, nine surveys over nine separate days were performed (Table 1).

\section{2) Tidal Stages}

It is recommended that vessel-mounted ADCP surveys be carried out at a peak spring tide to understand the flow at its strongest (Legrand 2009; Venugopal et al. 2011). Unfortunately, weather and wave conditions did not allow us to survey in the Inner Sound on these days. Instead, our surveys were executed during different phases of the spring/neap, and of the semidiurnal tidal cycles (Table 1). Initial exploratory surveys were performed over 2 days during flood tide ( 2 and 15 April), and 2 days during ebb tide ( 7 and 8 April). The results of these four surveys were combined to help identify a smaller area with the greatest potential as a tidal energy site. The selected area was subsequently surveyed as the tide turned; either from flood to ebb (29 April and 23 July) or from ebb to flood (4 June and 1 July), at a variety of stages of the spring/neap cycle. In addition, one shorter ebb tide survey was performed on 29 October, after the peak flow and before the turning of the tide. Using all the information, we selected two promising site locations and extrapolated the currents derived for these sites to peak spring tide with the help of the ORKM tidal predictions (section 3e).

\section{b. Underway ADCP measurements}

A broadband ADCP, the 300-kHz Teledyne RD Instruments WorkHorse Sentinel, was mounted on a davit off the side of ERI Aurora with its transducer head roughly $1 \mathrm{~m}$ below the water surface and beam 3 rotated $45^{\circ}$ away from the ship's centerline. The vessel's speed was typically 5-6 kt for the majority of the tracks, but if we motored with (against) the flow, it could be over $8 \mathrm{kt}$ (under $3 \mathrm{kt}$ ). Transects were regularly spaced across the tidal site and approximately perpendicular to the principal flow direction if the currents allowed. Single-ping bottom tracking was enabled to correct for the vessel's movements. Fong and Monismith (2004) show evidence that near the coast, in spite of a very accurate bottomtracking system, broadband ADCPs may still exhibit a significant bias that manifests itself as an overestimated velocity in the direction of boat motion. This bias is several centimeters per second in magnitude and can exhibit a vertical structure. For this reason, it is advised that each transect consists of a traverse in both directions to remove any bias (Legrand 2009; Venugopal et al. 2011). This was not realistic in the current study because of the fairly large survey areas; instead, alternate transects were sailed in an opposite direction $\sim 1 \mathrm{~km}$ across the flow (e.g., Fig. 7). The ADCP was set for twelve 2-m bins, and a 2-m blanking distance. All original current data are publicly available through the British Oceanographic Data Centre (BODC; https://www.bodc. ac.uk/data/information_and_inventories/edmed/search/). We examined data from the first, fourth, and sixth bin, relating to respective depths of about 5,11 , and $15 \mathrm{~m}$. The ADCP was set to ping as fast as possible, meaning two pings per second $(2 \mathrm{~Hz})$-one for current profiling and one for bottom tracking. The ADCP data were merged with navigation data provided by an onboard Raymarine GPS system, and averaged every $15 \mathrm{~s}$. This 
TABLE 2. Latitudes $\left({ }^{\circ} \mathrm{N}\right)$ and longitudes $\left({ }^{\circ} \mathrm{W}\right)$ of POLPRED grid points that were used in the time-correction method (see Fig. 2). The grid points are the centers of the $30^{\prime \prime} \times 1^{\prime}$ model's grid boxes.

\begin{tabular}{|c|c|c|c|c|c|c|}
\hline W0 & W1 & W2 & $\mathrm{C} 1$ & $\mathrm{C} 2$ & E1 & E2 \\
\hline $58^{\circ} 39^{\prime} 45^{\prime \prime}$ & $58^{\circ} 39^{\prime} 45^{\prime \prime}$ & $58^{\circ} 39^{\prime} 45^{\prime \prime}$ & $58^{\circ} 39^{\prime} 45^{\prime \prime}$ & $58^{\circ} 39^{\prime} 45^{\prime \prime}$ & $58^{\circ} 39^{\prime} 45^{\prime \prime}$ & $58^{\circ} 39^{\prime} 45^{\prime \prime}$ \\
\hline $3^{\circ} 10^{\prime} 30^{\prime \prime}$ & $3^{\circ} 9^{\prime} 30^{\prime \prime}$ & $3^{\circ} 8^{\prime} 30^{\prime \prime}$ & $3^{\circ} 7^{\prime} 30^{\prime \prime}$ & $3^{\circ} 6^{\prime} 30^{\prime \prime}$ & $3^{\circ} 5^{\prime} 30^{\prime \prime}$ & $3^{\circ} 4^{\prime} 30^{\prime \prime}$ \\
\hline W5 & W4 & W3 & $\mathrm{C} 4$ & $\mathrm{C} 3$ & $\mathrm{E} 4$ & E3 \\
\hline $58^{\circ} 39^{\prime} 15^{\prime \prime}$ & $58^{\circ} 39^{\prime} 15^{\prime \prime}$ & $58^{\circ} 39^{\prime} 15^{\prime \prime}$ & $58^{\circ} 39^{\prime} 15^{\prime \prime}$ & $58^{\circ} 39^{\prime} 15^{\prime \prime}$ & $58^{\circ} 39^{\prime} 15^{\prime \prime}$ & $58^{\circ} 39^{\prime} 15^{\prime \prime}$ \\
\hline $3^{\circ} 10^{\prime} 30^{\prime \prime}$ & $3^{\circ} 9^{\prime} 30^{\prime \prime}$ & $3^{\circ} 8^{\prime} 30^{\prime \prime}$ & $3^{\circ} 7^{\prime} 30^{\prime \prime}$ & $3^{\circ} 6^{\prime} 30^{\prime \prime}$ & $3^{\circ} 5^{\prime} 30^{\prime \prime}$ & $3^{\circ} 4^{\prime} 30^{\prime \prime}$ \\
\hline Land & S1 & S2 & S3 & S4 & Land & Land \\
\hline $58^{\circ} 38^{\prime} 45^{\prime \prime}$ & $58^{\circ} 38^{\prime} 45^{\prime \prime}$ & $58^{\circ} 38^{\prime} 45^{\prime \prime}$ & $58^{\circ} 38^{\prime} 45^{\prime \prime}$ & $58^{\circ} 38^{\prime} 45^{\prime \prime}$ & $58^{\circ} 38^{\prime} 45^{\prime \prime}$ & $58^{\circ} 38^{\prime} 45^{\prime \prime}$ \\
\hline $3^{\circ} 10^{\prime} 30^{\prime \prime}$ & $3^{\circ} 9^{\prime} 30^{\prime \prime}$ & $3^{\circ} 8^{\prime} 30^{\prime \prime}$ & $3^{\circ} 7^{\prime} 30^{\prime \prime}$ & $3^{\circ} 6^{\prime} 30^{\prime \prime}$ & $3^{\circ} 5^{\prime} 30^{\prime \prime}$ & $3^{\circ} 4^{\prime} 30^{\prime \prime}$ \\
\hline
\end{tabular}

resulted in a spatial resolution along the tracks of about 40-50 m for most measurements. According to Legrand (2009), a 5-m depth for the first bin, a sampling rate of $2 \mathrm{~Hz}$, and horizontal bins of $50 \mathrm{~m}$ are suitable settings for a transect survey. ADCP velocity errors after 15-s averaging varied around $3.5,6$, and $7 \mathrm{~cm} \mathrm{~s}^{-1}$ for corresponding depths of 5,11, and $15 \mathrm{~m}$. These errors implied a (signal-to-noise ratio) SNR $={ }^{10} \log$ (current speed/error speed) in the first bin from roughly $2 \mathrm{~dB}$ (peak currents) to $1.3 \mathrm{~dB}$ (currents during slack tide). The errors in direction are not given. The current speed magnitudes and directions were horizontally mapped for the three depths after correcting for temporal differences between the sample locations during a survey, as described in the following section.

\section{c. Time correction using model data}

The observed currents were necessarily affected by tidal changes over the period of a survey, and even over individual tracks. These current changes were estimated using ORKM. For each survey, we obtained 10-min interval predictions of depth-averaged current speed and direction at each of the 18 grid points defining the survey area (Table 2; Fig. 2). These time series were used to remove the temporal distortion and derive snapshots of the tidal current texture in the Inner Sound at midtrack time.

Note that this procedure is distinct from existing methods. For example, "detiding techniques" instead aim to separate tidal from nontidal currents that are driven by causes such as wind and density differences. Foreman and Freeland (1991) use a numerical model to predict the tidal current at each observation location and time, and remove it from the ADCP velocities to examine the residual field flow. Another approach is performing a harmonic analysis on the current data, if enough measurements are available to construct a time series of the currents at each chosen location. Such analysis was applied to data obtained during repeated tracks across a tidal channel (Simpson et al. 1990;
Vennell 1994; Epler et al. 2010). Candela et al. (1992) makes this technique applicable to data that are also a function of horizontal coordinates $(x, y)$, as is generally the case with ship-mounted ADCP data, and Münchow (2000) extends it to three dimensions. Geyer and Signell (1990) combine underway ADCP data from eight separate "repeat-track" cruises and a time series generated by the average current data from four moored ADCPs in the area. They use harmonic analysis to apply a phase shift to the cruise data so that all data represent a chosen tidal phase, followed by a spatial interpolation of the data to a uniform grid. Thus, spatial representations of the tidal flow around a headland at different tidal stages are composed. Spatiotemporal fitting based on harmonic analysis has been the most widely used and developed (see e.g., Vennell 2006; Vazquez et al. 2011). Our method can be applied to a single survey, or more generally where there is insufficient data for harmonic analysis to be realistic. Our method requires only a fairly rudimentary numerical model of the tides that is used solely to predict the local rate of change of current speed and direction (these will be particularly sensitive to the phasing of the tide). Those predictions are used to correct survey measurements taken over a period to the tidal current at a single chosen time as a function of position.

We explain our method in the following by taking the first survey of 2 April as an example. ORKM data for this day are plotted in Fig. 3. We first fitted the ORKM current speed data as a function of $d t=t-t_{o}$, to a secondorder polynomial, $P(d t)$, applying Matlab function "polyfit." The reference time $t_{o}$ was chosen to be midtrack time so that the change in speed $m$ at a grid point compared to midtrack time could be calculated with

$$
d m(d t)=P(1) d t^{2}+P(2) d t .
$$

These model-derived $d m$ values were then spatially interpolated to the ADCP sample locations and subtracted 

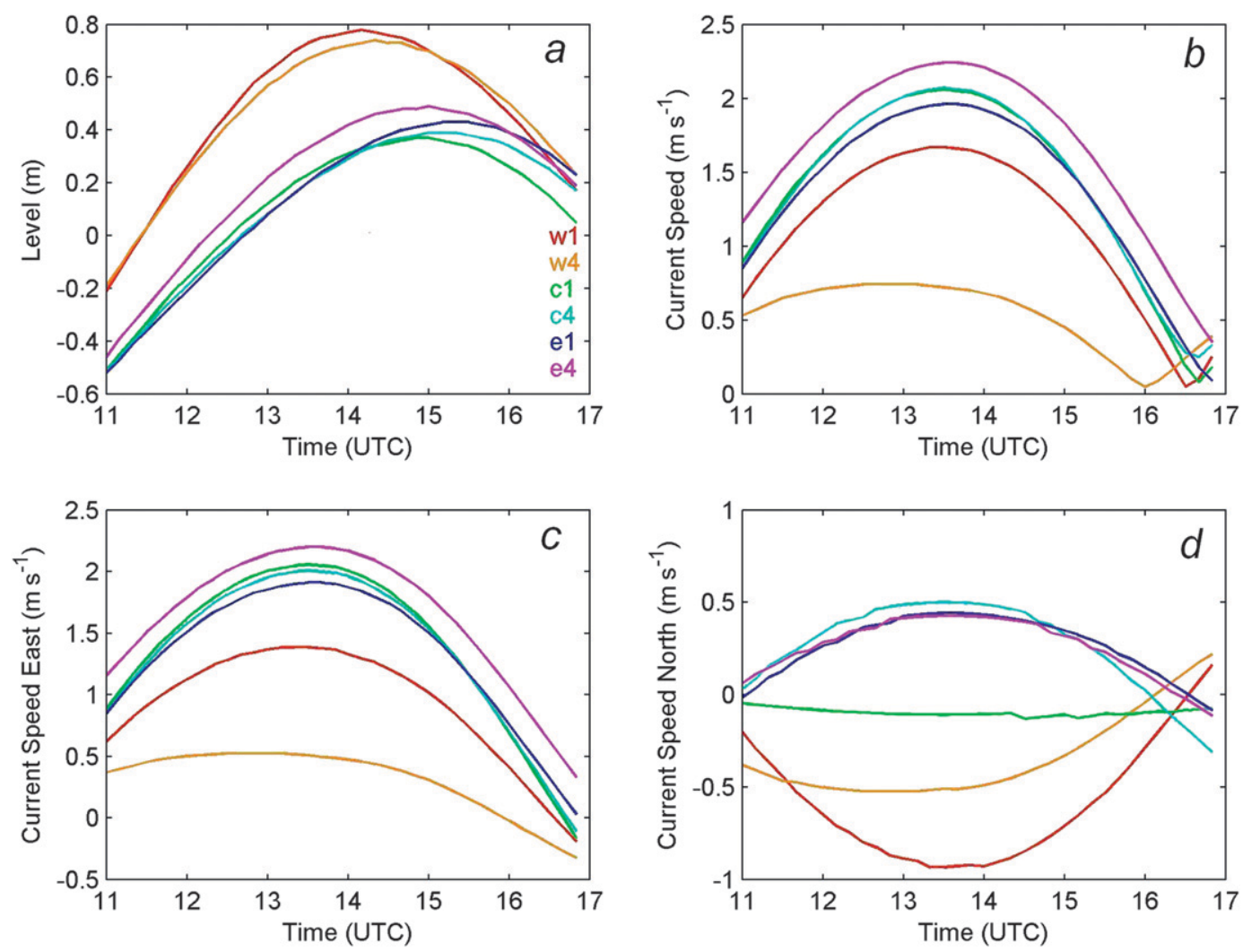

FIG. 3. POLPRED's ORKM time series of 10-min-interval predictions for 2 Apr 2009, for grid points w1 (red), w4 (orange), c1 (green), c4 (cyan), e1 (blue), and e4 (magenta), of (a) level, datum: mean sea level (MSL); (b) current speed, $\mathrm{m} \mathrm{s}^{-1}$; (c) east component of current velocity, $u=m \sin (d)$, with $d$ as direction (compass); and (d) north component of current velocity, $v=m \cos (d)$. Model data of the other grid points are not shown to improve clarity.

from the measured currents. The results were current speed estimations at all sample locations at midtrack time. (It is possible to select another reference time, but midtrack time should optimize results.) For the very few measurements outside the model area, the closest grid point was used, while for the three grid points on land, the current speed was set to zero. The differences in the north and east components of the current velocity were calculated in a similar fashion, to derive the change in current direction. The corrected transect data were then horizontally and linearly interpolated using Matlab function "griddata.m." The transect data could be interpolated along the isobaths (depth contours) before the horizontal interpolation, but a comparison shows that this does not necessarily improve the accuracy of the current flow mappings (Gooch et al. 2009). Because we could not assume that the flows in the Inner Sound closely followed the contours of the seafloor, we chose to ignore the bathymetry in our interpolation.

Critical to this method is the accuracy with which the model replicates the phasing of the tides. We assessed model skills in tidal phasing by comparing model tidal elevations with observed and predicted values at a number of port locations in and around the Pentland Firth. This analysis was performed for the 3-month period of April-June 2009, coinciding with the majority of the ADCP surveys. The results showed that the model predicted the timing of high and low water with an error of $\sim 10$ min. Furthermore, a tidal analysis of elevations revealed that the model predicted the phasing of the dominant $M_{2}$ tidal constituent within $2^{\circ}(\sim 4 \min )$ of charted values. This result gave confidence in the model's ability to replicate tidal phasing with a degree of accuracy appropriate for the time-correction method employed.

The method is visualized in Fig. 4, using current data from the first bin at 5-m depth. On 2 April, three transects were conducted around high water (HW) in the flood tide (Fig. 4, top). The first (most northerly) track was conducted between 1126 and 1159 UTC, the second (middle) transect between 1246 and 1302 UTC, and the third (most southerly) transect between 1436 and 1503 UTC. The flood flow was too strong to motor the vessel perpendicular to the flow direction, so all transects were surveyed from west to east following the flood flow 

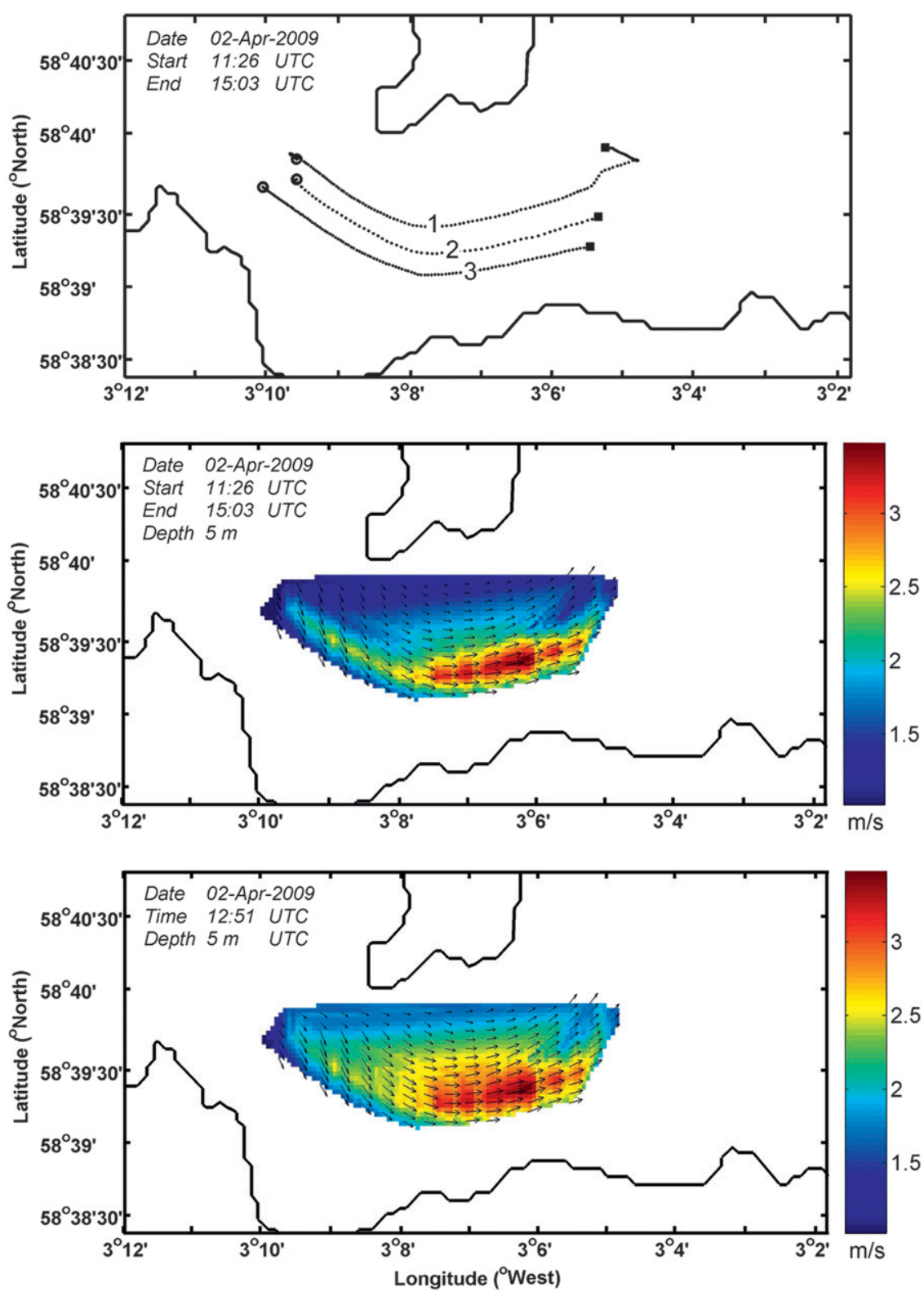

FIG. 4. Example of surveying method, using survey on 2 Apr 2009. (top) Survey tracks that were followed; each dot signifies a 15-s average, and circle and square indicate the start and end of a track, respectively; (middle) the measured current speeds (directions) interpolated to $x_{i}=$ $0.001^{\circ}\left(0.005^{\circ}\right)$ longitude by $y_{i}=0.0005^{\circ}\left(0.001^{\circ}\right)$ latitude grid; (bottom) same as above, only the current velocities have been interpolated to midtrack time first.

(possibly introducing a small bias error). The large intervals between transects represent the time it took to bring the davit on board, motor against the flow, and redeploy the davit and ADCP. The first transect was performed when that flood flow was strengthening and the third transect as it started to weaken (Fig. 3b). This partly explained the narrow width of the core of the flow as seen in the map of uncorrected currents (Fig. 4, middle). If the time correction was applied, and all currents were extrapolated to midtrack time, 1251 UTC, the band of stronger speeds was still apparent but was much broader in the north-south direction (Fig. 4, bottom). Also, the corrected currents were generally raised, because midtrack time was expected near the peak flow in the area. The result was a distinct core of stronger currents. The timecorrection procedure was repeated for the current measurements at 11 - and 15 -m depths; the results were not very different from the ones derived for 5-m depth. At the end 
of the first track, in the northeastern corner slightly north of e1 near $\left(58^{\circ} 39^{\prime} 55^{\prime \prime} \mathrm{N}, 3^{\circ} 5^{\prime} 10^{\prime \prime} \mathrm{W}\right)$, ADCP retrieval errors occurred at depths over $13 \mathrm{~m}$. These errors could possibly be attributed to the sharp corner at the end of the vessel track (Fig. 4, top), or they could also be associated with suspended sediment and enhanced turbulence in the area (Easton et al. 2011). The consequences of the spatiotemporal interpolations for the accuracy of the derived currents will be calculated and discussed in section $3 \mathrm{c}$.

\section{Results and discussion}

\section{a. Initial surveys of the ebb and flood flow}

The time corrections of the current velocities for the later surveys (7, 8, and 15 April) resulted in adjustments similar to those derived for the survey on 2 April. We used time-corrected data of the surveys to explore the ebb and flood flows in the Inner Sound. Unlike the current speeds, the current directions were expected to be fairly steady during either ebb flow or flood flow, except very close to the turn of the tide. It is reasonable therefore to combine directions from different days to give a "summary view" of directions. The compositions of all flood flow data (2 and 15 April) and all ebb flow data (7 and 8 April) are shown in Fig. 5. It illustrates how during the flood tide water moved from west to east, and during ebb tide from east to west. Note that the speeds will be strongly influenced by timing within the spring/ neap cycle (i.e., currents can be twice as strong for an extreme spring tide as they are at neap tides), and also precise timing within each semidiurnal tide (the peak flood or ebb flow is reasonably steady for $2 \mathrm{~h}$ but weakens considerably outside of the tolerance). Thus, the results for current speed should be treated with considerable caution. In particular, it should be considered that both flood tide surveys were conducted close to neap tide, when currents should have been atypically low. In fact, the highest measured currents (Fig. 4) greatly exceed the model predictions of the flood flow at 2 April (Fig. 3). This underestimation by the model was also seen for the following survey days. The maximal measured currents (ORKM currents) on 2, 7, 8, and 15 April were, respectively, 3.60 (2.37), 3.76 (3.02), 3.99 (3.25), and $3.47(2.45) \mathrm{m} \mathrm{s}^{-1}$. This implied that the currents in the core of the flow were 1.2-1.5 times faster than the model predicted. The two ebb tide surveys were conducted in more average conditions, which probably explained why the ebb flow magnitudes exceeded the flood flow. There is a notable displacement in the regions of strongest currents between the ebb tide and the flood tide. It can be seen from the plot showing transects on all 4 days (Fig. 5, top) that the gridded values of both ebb and flood flow are fairly well supported by data, but there may be significant extrapolation or interpolation errors. For example, the first transect on 15 April, the only one in the northeast during flood tide, was very early in the flood flow, so the anomalous direction of the flow in this region (Fig. 5, middle) may be unrepresentative. The ebb and flood flows both show a curvature (Fig. 5), which is as would be expected from the steering of the flow by the bathymetry (Easton et al. 2011). Thus, the ebb and flood flows were opposed at each location, but this opposition was not rectilinear. The angle between flood and ebb showed strong evidence that ebb and flood flow directions were far from opposite in the west. This is related to the core of the flood flow being directed at approximately $140^{\circ}$, a significantly more southerly angle than the ORKM predicted. Rectilinear flow appears to be better in the east of the sound, but there are some significant issues locally here. In the following, we analyze these issues in more detail by mapping the conditions considered to be relevant for a tidal energy site.

We characterized as sites favorable for exploitation the regions where

(i) speeds of both ebb and flood flow were high,

(ii) misalignment angles between the ebb and flood flow were minimal, and

(iii) speeds of ebb and flood flow were nearly equal in size.

Parameters related to (i), (ii), and (iii) are mapped in Figs. 6a,b,d. Figure 6c illustrates a combination of (i) and (ii) by plotting the scalar products of ebb and flood flow velocity. (For two vectors of magnitude " $x$ " and " $y$ " and at a relative angle " $\theta$," the scalar product equals " $x y \cdot \cos \theta$," which equals " $-x y$ ” for precisely opposing vectors. Large negative values of scalar product require strong and opposing ebb and flood currents and thus Fig. $6 \mathrm{c}$ is useful in identifying candidate areas for tidal stream energy.) The ORKM grid points are plotted in these figures to help refer to the locations in the Inner Sound.

The map of the average current speed including both ebb and flood flows (Fig. 6a) implies that the strongest currents were located west of $\mathrm{c} 1-\mathrm{c} 4$ (longitude $>$ $\left.3^{\circ} 7^{\prime} 30^{\prime \prime} \mathrm{W}\right)$. However, in this area the misalignment between ebb and flood flow exceeded $20^{\circ}$, with a misalignment of $\sim 40^{\circ}$ around point w2 (Fig. 6b). For horizontal fixed-axis tidal turbines, the dominant design concept to date, this could present a major detriment to the efficient harnessing of this resource. It is not clear how big a misalignment angle is acceptable and probably this varies among devices. Following the guidelines of the European Marine Energy Centre (EMEC), a directionality offset needs to be applied if the flow deviates from the major axis by more than $10 \%$ for over $5 \%$ of the time (Legrand 2009). If the tidal turbine is 

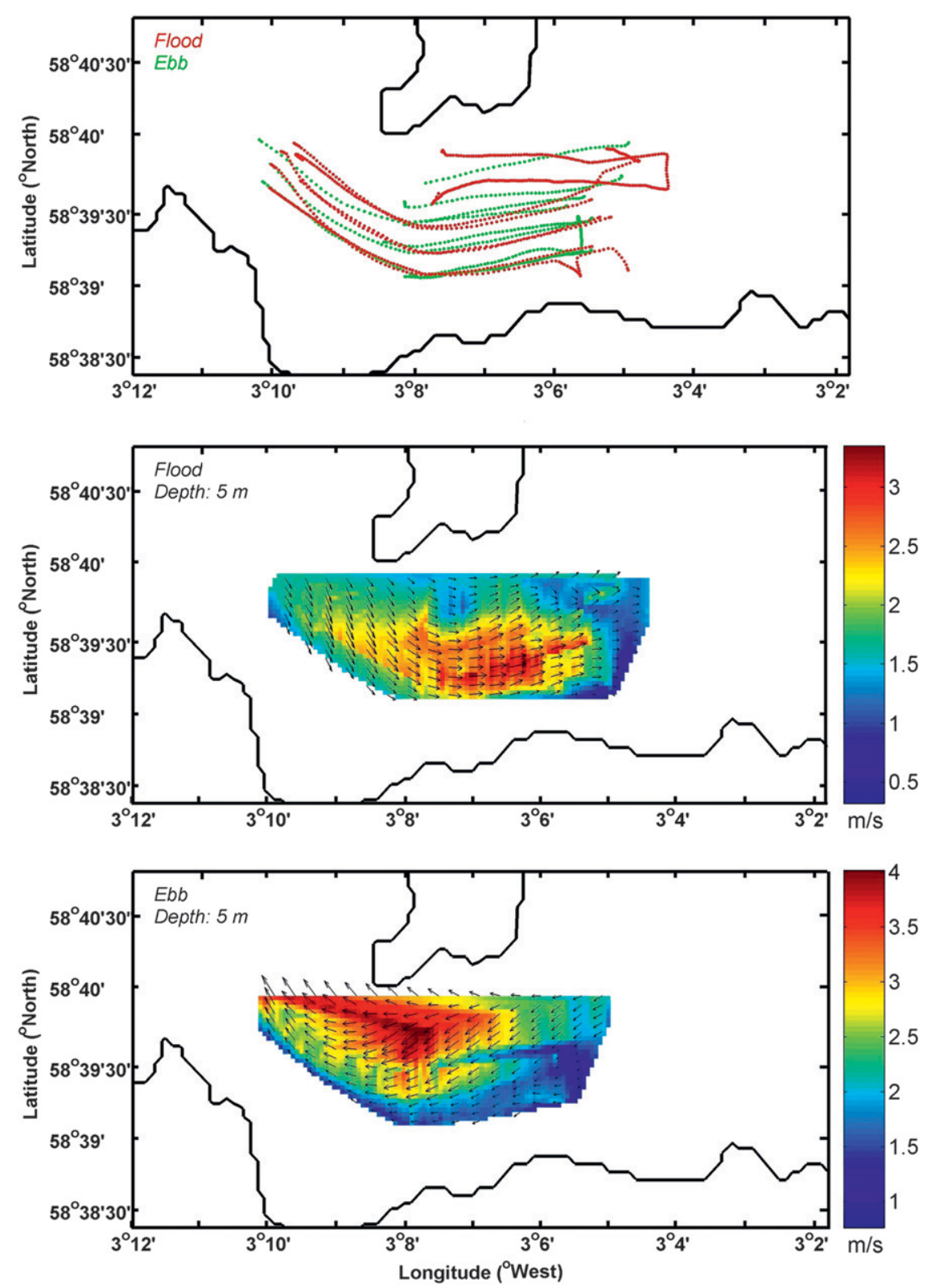

FIG. 5. Composites of initial surveys, with measured current velocities of each survey interpolated to midtrack time. (top) As in Fig. 4, but tracks followed during flood flow are indicated in red, and during ebb flow in green; (middle) flood flow data combined ( 2 and $15 \mathrm{Apr}$ ); (bottom) ebb flow data combined (7 and 8 Apr).

a vertical axis machine or can align with the flow this offset is less relevant, but the issue of directionality should still be considered in relation to the forces on the support structure. In the most northwesterly corner of our survey area, near w1, the misalignment was less than $20^{\circ}$, but our own experience and local knowledge indicated that the wave climate in this region was too hazardous to be considered safe. East of c2-c3 (longitude $\left.<3^{\circ} 6^{\prime} 30^{\prime \prime} \mathrm{W}\right)$ the currents were significantly weaker, but the ebb and flood flow were generally well aligned except for the most northeasterly corner just north of e1. This anomaly coincided with the residual (flood-ebb) current field, calculated using numerical modeling, that is cyclonic around e1 (Easton et al. 2011). Figure 6c implied that the center of the Inner Sound, in the middle of c1, c2, c3, and c4, was a favorable location.

Regarding asymmetry between ebb and flood current speed, if the flow in one direction is much stronger than 

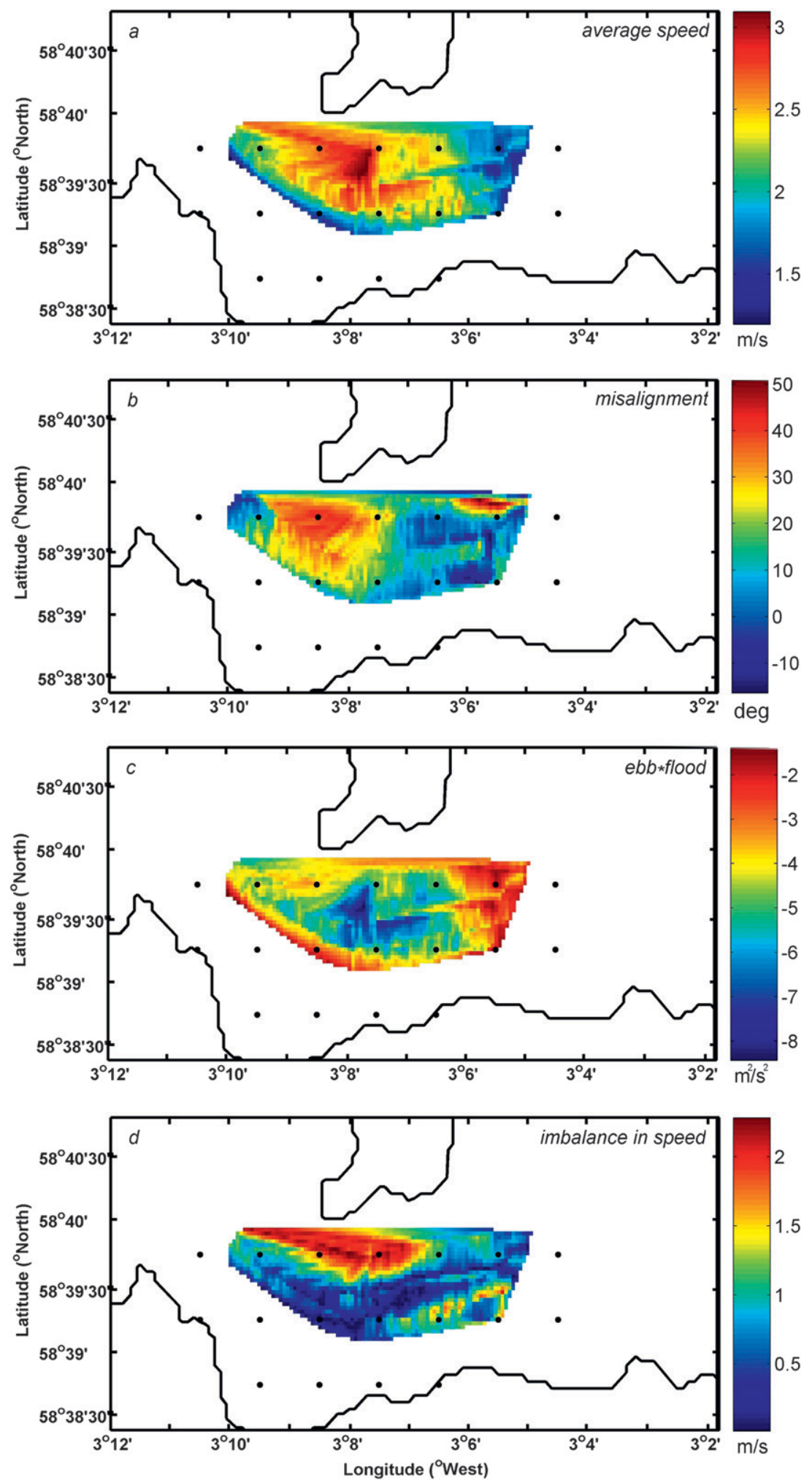

FIG. 6. Examinations of combined flood and ebb flow measurements (Fig. 5), fitted to $x_{i}$ and $y_{i}$ and time corrected as in bottom panel of Fig. 4; the black dots indicate the grid points (Fig. 2; Table 2) for reference. (a) Average speed (flood speed + ebb speed)/2; (b) misalignment angle between ebb and flood flow, $\mid(180$ - (ebb direction - flood direction)|; (c) scalar product of ebb velocity and flood velocity; and (d) imbalance in ebb and flood speed, |ebb speed - flood speed|. 

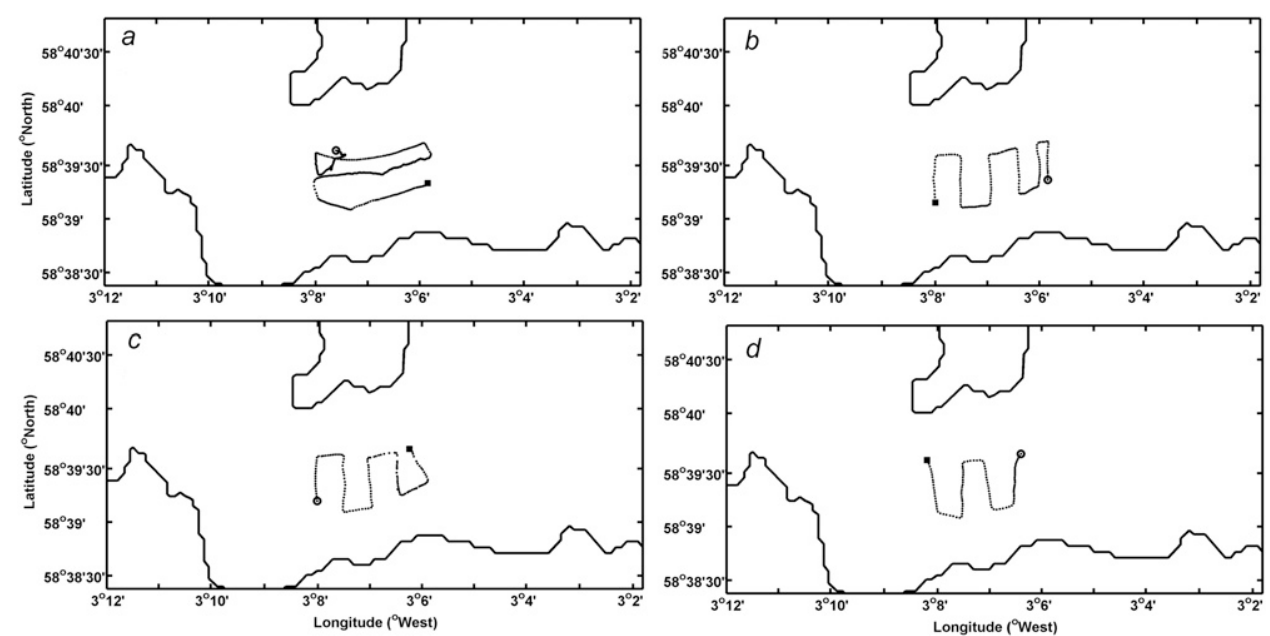

FIG. 7. Example of survey tracks that were followed during repeat surveys, using survey on 29 Apr 2009; each dot signifies a 15-s average, and circle and square indicate the start and end of a track, respectively. (a) 1145-1325, (b) 1325-1403, (c) 1404-1438, and (d) 1439-1506 UTC.

the other, then energy development is compromised since the design of the tidal energy device configured for one flow may be less efficient for the other. The observed asymmetry was smallest in the center of the Inner Sound, in a narrow channel between the lines w2-c2 and w3-c3, and largest near the southwest of Stroma, west of $\mathrm{c} 1$ near and north of w0-w2 (Fig. 6d). This imbalance in speed will be affected by biases associated with the semidiurnal and spring/neap cycles in "midtrack times" between the ebb and flood observations and therefore Fig. 6d should be treated with caution. A fuller analysis requires the correction of each set ("normalization") to a standard case (e.g., peak ebb or flood flow at spring tide).

The horizontal plots for 5-m depth (e.g., Fig. 4) were very similar to those for 11- and 15-m depth (not shown), and hence a strong vertical shear was not observed over these depths. The survey mean vertical shear (defined as the current speed difference between bins/distance between bins) between 5- and 11-m depth ranged from 0 to $0.01 \mathrm{~s}^{-1}$ and between 11- and 15-m depth from 0.01 to $0.02 \mathrm{~s}^{-1}$ with standard deviations of the mean of 0.02 and $0.04 \mathrm{~s}^{-1}$, respectively. During the second flood survey on 15 April, ADCP retrieval errors occurred at depths greater than $18 \mathrm{~m}$, near $\mathrm{c} 2\left(58^{\circ} 39^{\prime} 40^{\prime \prime} \mathrm{N}, 3^{\circ} 6^{\prime} 25^{\prime \prime} \mathrm{W}\right)$. This location did not correspond with any changes in vessel motion (Fig. 5, top), and hence this could not explain the retrieval error. During the two ebb flow surveys, retrieval errors were not observed. Based on the above findings, we decided to focus on the region near the center of the Inner Sound for our study of the current patterns during the turn of the tide.

\section{b. Surveys of a limited area spanning the turn of the tide}

A series of surveys were conducted in a relatively limited area corresponding to the area enclosed by w2, w3, e1, and e4 (Fig. 2), between $58^{\circ} 39^{\prime} 15^{\prime \prime}$ and $58^{\circ} 39^{\prime} 45^{\prime \prime} \mathrm{N}$ latitude and $3^{\circ} 8^{\prime} 30^{\prime \prime}$ and $3^{\circ} 5^{\prime} 30^{\prime \prime} \mathrm{W}$ longitude. Although initial surveys had demonstrated promising results, several significant issues still required addressing. Surveys were necessary to try and identify precisely where developments could be sited in terms of flow characteristics and stresses on the turbines, and generally to anticipate conditions at proposed sites. Surveys were conducted as the tide turned, either from flood to ebb or from ebb to flood, and at a variety of stages of the spring/neap cycle (Table 1). Because a limited area was covered, repeating tracks were achievable showing the development of the tidal current patterns over a limited period of time. We use the first such repeat survey, on 29 April, to detail our methodology.

On this day, the currents were expected to be near average between neap and spring, and HW was predicted around 1230 UTC. Figure 7 illustrates the four consecutive tracks that were followed. During the first track the tide was flooding strongly from west to east, the flood flow weakened during the second track, the third track was throughout slack tide, and during the fourth track the tidal currents were reversed. The measured currents were highest during the first track, with maximal values of $4 \mathrm{~m} \mathrm{~s}^{-1}$, and lowest during the third track when currents did not exceed $1 \mathrm{~m} \mathrm{~s}^{-1}$. A course perpendicular to the current, as illustrated by the last three tracks (Figs. 7b-d), would be preferred (Gooch et al. 2009; Venugopal et al. 

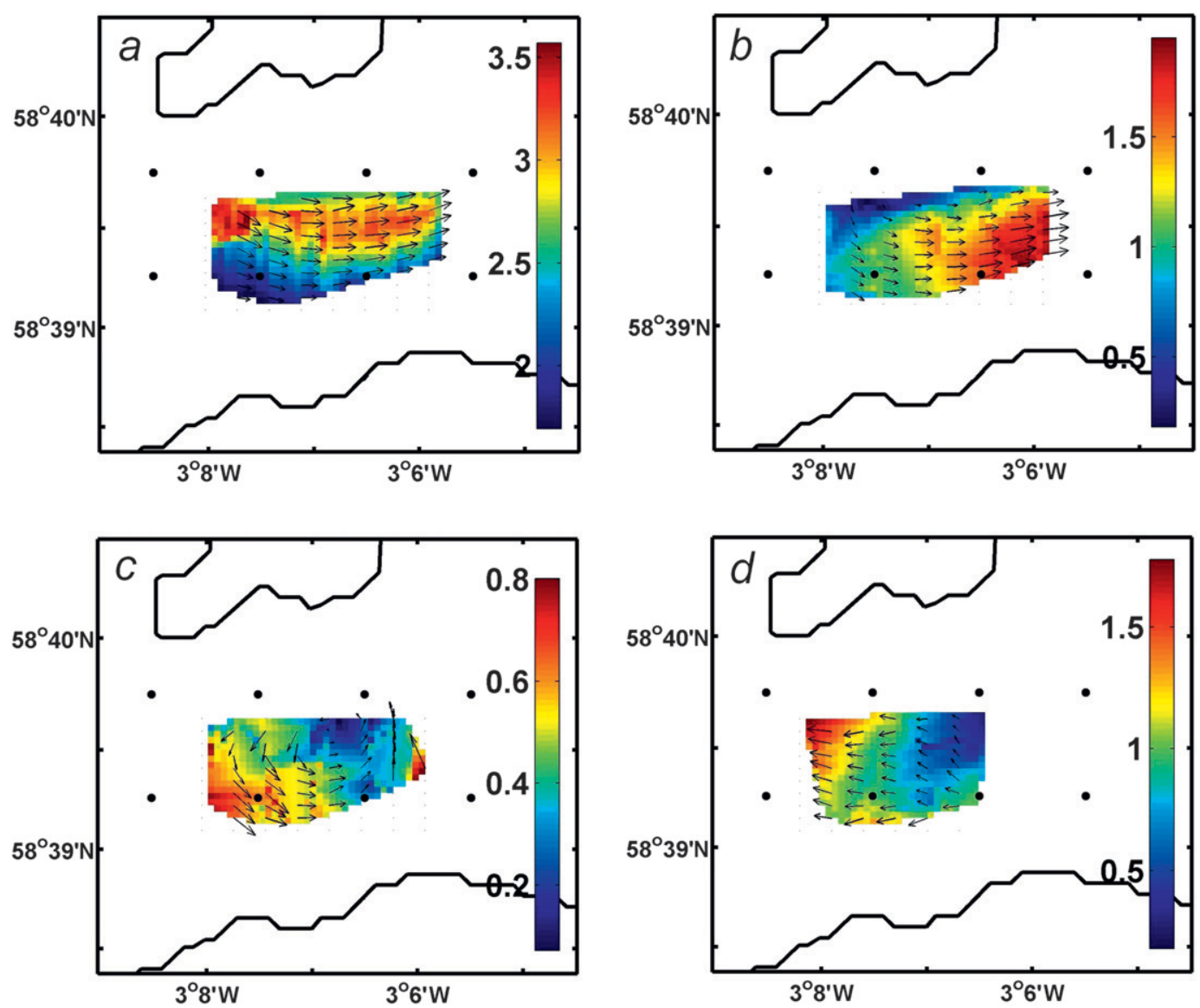

FIG. 8. The measured current speeds in meters per second (directions) at 5-m depth, interpolated to $x_{i}=0.001^{\circ}$ $\left(0.005^{\circ}\right)$ longitude by $y_{i}=0.0005^{\circ}\left(0.001^{\circ}\right)$ latitude grid for $29 \mathrm{Apr} 2009$. (a) $1145-1325$, (b) 1325-1403, (c) 1404-1438, and (d) 1439-1506 UTC.

2011), but the flood flow at the start was too strong for our boat to cross safely, and the legs were aligned with the current (Fig. 7a).

The mapped current speeds (Fig. 8) and corresponding maps of the current interpolated to midtrack time (Fig. 9) illustrated that time correction produced relatively small changes in velocity texture. The biggest effect was seen for the first track; this was not surprising as, of the four tracks, the first was the longest one (100 $\mathrm{min})$. Here, a strong narrow flood flow from west to east in the middle of the channel was apparent (Fig. 8a). The time correction moved the core of the flood flow slightly southward, to between $58^{\circ} 39^{\prime} 20^{\prime \prime}$ and $58^{\circ} 40^{\prime} \mathrm{N}$, and removed the concentration of high currents in the northwestern corner located near the start of the track (Fig. 9a). The narrowness of the flood stream was unchanged by the time correction, and did therefore not appear to be a consequence of transects being parallel to the stream direction. On first analysis, the appearance of stronger currents to the east during the second track (Fig. 8b) might have been attributed to the progress of the survey from east to the west in a weakening flood flow. Similarly, the stronger currents to the west during the final track (Fig. 8d) might have been attributed to the progress to the west in a strengthening ebb flow. After time correction, however, these characteristics were not eliminated (Figs. 9b,d), implying that these are "real" features of the flow. Figure 9c is the most interesting and shows strong evidence of a cyclonic (counterclockwise) eddy southwest of $\mathrm{c} 2$ around $\left(58^{\circ} 39^{\prime \prime} 30^{\prime} \mathrm{N}, 3^{\circ} 6^{\prime} 45^{\prime \prime} \mathrm{W}\right)$. This is significant, as cross currents up to $0.5 \mathrm{~m} \mathrm{~s}^{-1}$ were measured in the middle of the channel (northerly currents at $\sim 3^{\circ} 6^{\prime} 15^{\prime \prime} \mathrm{W}$ and southerly currents at $\sim 3^{\circ} 7^{\prime} 30^{\prime \prime} \mathrm{W}$ ). Relatively benign conditions were apparent between $3^{\circ} 7^{\prime}$ and $3^{\circ} 6^{\prime} 30^{\prime \prime} \mathrm{W}$. An eddy here is not predicted by ORKM, but the model does predict that the tide will turn earlier in the north of the Inner Sound than in the south, which would generate the appropriate vorticity.

Maps of the currents at 11- and 15-m depths showed only small differences from those at 5-m depth. During flood flow (track 1), the means of the current speed differences between 5 and $11 \mathrm{~m}$ and between 11 and 

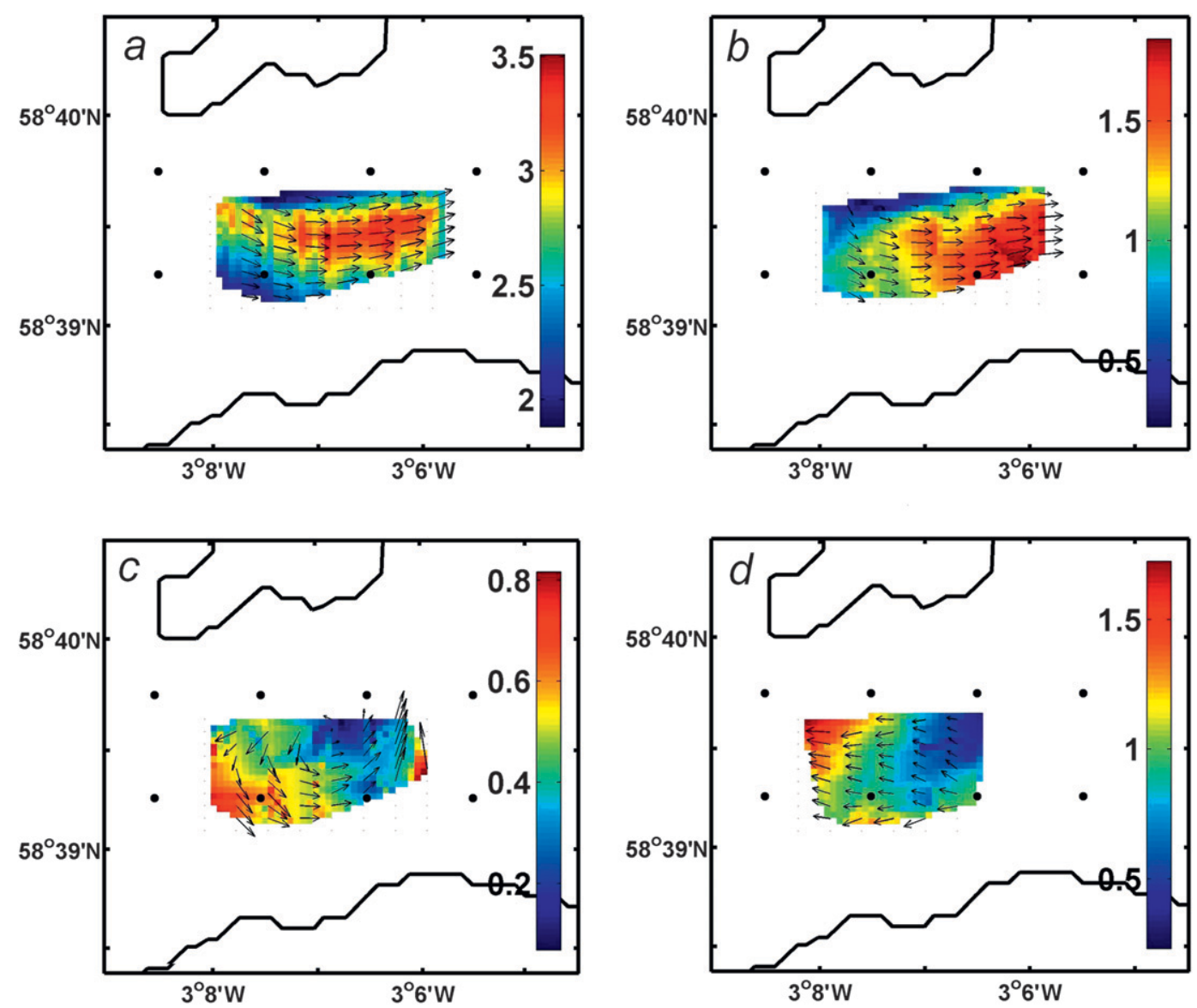

FIG. 9. As in Fig. 8, but the current velocities have been interpolated to midtrack time first, being (a) 1235, (b) 1344, (c) 1420 , and (d) 1453 UTC.

$15 \mathrm{~m}$ were $0.1 \pm 0.2 \mathrm{~m} \mathrm{~s}^{-1}$ for both, resulting in mean vertical shears of $0.02 \pm 0.03$ and $0.025 \pm 0.05 \mathrm{~s}^{-1}$, respectively. The quoted variations are the standard deviations of the means and signify that spatial variation of shear was large. During the turn of the tide (track 3), the mean current speed difference (vertical shear) between 5 and $11 \mathrm{~m}$ was about $0.03 \pm 0.1 \mathrm{~m} \mathrm{~s}^{-1}\left(0.005 \pm 0.02 \mathrm{~s}^{-1}\right)$, while between 11 and $15 \mathrm{~m}$ it was $\pm 0.1 \mathrm{~m} \mathrm{~s}^{-1}\left( \pm 0.02 \mathrm{~s}^{-1}\right)$. These shear values, similar to those found by Gooch et al. (2009) in Marrowstone Island, Puget Sound, implied that the vertical shear was small compared to the measured current speeds. Excessive ADCP measurement errors were not apparent in spite of the rapid turning at the start of the first track.

The time correction used in this paper, based on the interpolation of current changes in space, gave slightly different results than a simpler approach whereby current changes were averaged over grid points $\mathrm{c} 1, \mathrm{c} 2$, c3, and c4 (Goddijn-Murphy and Woolf 2009). The differences were most obvious for tracks 2 and 3, for which the latter approach seemed to overestimate the changes.

\section{c. Assessment of interpolation errors}

\section{1) TEMPORAL INTERPOLATION}

We verified that a possible phase shift between the ORKM model and measured currents was not significant for the grid points $\mathrm{c} 1, \mathrm{c} 2, \mathrm{c} 3$, and $\mathrm{c} 4$ using data from 29 April and 1 July. Averaging the ADCP current speed in the $0.5^{\prime}$ latitude $\times 1^{\prime}$ longitude grid boxes around these points over 10-min intervals, doing the same for ADCP current direction, and comparing the results with coinciding ORKM predictions did not reveal evidence of a phase error greater than $10 \mathrm{~min}$. (We selected grid points $\mathrm{c} 1-\mathrm{c} 4$ to achieve the most matchups.) The consequences of a phase error $\Delta t$ were estimated by repeating the time correction with $d t=d t+\Delta t$ (1), using all surveys in April and on 1 July. This exercise revealed that $\Delta t=10 \mathrm{~min}$ would result in a mean absolute error (MAE) in current speed of $\sim 4 \mathrm{~cm} \mathrm{~s}^{-1}$ for the shorter tracks (half hour) and $\sim 10 \mathrm{~cm} \mathrm{~s}^{-1}$ for the longer tracks (over an hour). The error in direction was $\sim 0.6^{\circ}$ during ebb or flood, increasing to tens of degrees at the turn of the tide. 


\section{2) SPATIAL INTERPOLATION}

The spatial interpolation of the current speeds and directions to respective $0.001^{\circ} \times 0.0005^{\circ}(50 \mathrm{~m} \times 50 \mathrm{~m})$ and $0.005^{\circ} \times 0.001^{\circ}(250 \mathrm{~m} \times 100 \mathrm{~m})$ grids could introduce errors, as this grid resolution was comparable to the $\sim 50-\mathrm{m}$ resolution of the ADCP measurements along track but the distance between the legs of the tracks was typically $300 \mathrm{~m}$. The consequence was estimated by interpolating only ADCP sample points $300 \mathrm{~m}$ apart. The interpolation results for locations on the tracks were compared with the original ADCP data. The difference between the two values would give a high estimation of the error due to the spatial interpolation (high because less data are included). The results for all April surveys and 1 July showed that the consequent error in current speed was about $5-10 \mathrm{~cm} \mathrm{~s}^{-1}$. The error in current direction was $\sim 3^{\circ}$ during ebbing or flooding tide, increasing to $\sim 15^{\circ}$ during the turn of the tide.

\section{3) COMBINED ERRORS}

Adding all errors (spatial and temporal interpolation and ADCP measurement) with $\Delta x=\sqrt{\sum_{i}\left(\Delta x_{i}\right)^{2}}$ (Taylor 1982), it can be shown that the uncertainty in the timecorrected, spatially interpolated currents was approximately 0.15 (0.11) $\mathrm{m} \mathrm{s}^{-1}$ in magnitude for longer (shorter) tracks. The uncertainty in direction was estimated to be $\sim 3^{\circ}$ for surveys during ebb or flood flow, increasing to large uncertainties on the order of tens of degrees during the turn of the tide. The propagation of an error $\Delta x$ in a function $f$ of variable $x$ can be calculated using Taylor (1982):

$$
\Delta f=\left|\frac{d f}{d x}\right| \Delta x .
$$

Equation (2) can be used to estimate consequent errors in the chosen metrics, $f$, for tidal power site selection.

\section{d. Summary of the tidal surveys}

Detailed descriptions of the subsequent surveys, including the equivalent figures to Fig. 9, are given in the online supplement to this paper. The data showed that the tidal flows in the Inner Sound proved to be more complicated than anticipated at the outset. Several features of the currents, discussed in the following subsections, are considered important.

\section{1) StREngth}

In general, with speeds measured over $4 \mathrm{~m} \mathrm{~s}^{-1}$, the currents within the Inner Sound are strong enough to offer good potential for economical generation of tidal power. The uncertainty in average speed due to the $\sim 0.15 \mathrm{~m} \mathrm{~s}^{-1}$ uncertainties in derived ebb and flood flows was $\sim 0.1 \mathrm{~m} \mathrm{~s}^{-1}$ [Eq. (2)], small enough to distinguish its spatial pattern (Fig. 6a). Precise calculations on current statistics were difficult to establish because of the complexity of the observed flow, but currents are likely to be $\sim 35 \%$ stronger than the ORKM predictions within the "stream" of the flow. However, the current speeds of the flood stream north of $58^{\circ} 39^{\prime} 40^{\prime \prime} \mathrm{N}$ and of the ebb stream south of $58^{\circ} 39^{\prime} 30^{\prime \prime} \mathrm{N}$ are significantly lower. Currents are also too weak in the region east of $3^{\circ} 6^{\prime} \mathrm{W}$ (Fig. 6a).

\section{2) Misalignment OF EBB AND FLOOD}

An estimated error of $\sim 3^{\circ}$ in the derived flow directions during ebb and flood would propagate into an error of $\sim 4^{\circ}$ in misalignment [Eq. (2)], which is sufficiently small to identify sites where misalignment is acceptable. Misalignment over the whole width of the Inner Sound is judged to be acceptable east of $3^{\circ} 7^{\prime} \mathrm{W}$, and also in the northwest, west of w1 $\sim\left(58^{\circ} 39^{\prime} 45^{\prime \prime} \mathrm{N}\right.$, $\left.3^{\circ} 9^{\prime} 40^{\prime \prime} \mathrm{W}\right)$. In these regions, the ebb and flood current speeds are both reasonably large (Fig. 6a) and their imbalance tolerable (Fig. 6d). Misalignments of over $30^{\circ}$ were found in the western entrance to the Inner Sound; this is rather surprising in a tightly constrained tidal channel.

\section{3) ASYMMETRY OF EBB AND FLOOD FLOWS}

A key finding of this study in the Inner Sound is that the streams of the strongest ebb and flood flows are quite narrow and significantly displaced. This is of particular importance north of $58^{\circ} 39^{\prime} 40^{\prime \prime} \mathrm{N}$ and west of $3^{\circ} 6^{\prime} 30^{\prime \prime} \mathrm{W}$ (Fig. 6d), where the ebb stream is located well to the northwest of the flood stream (Fig. 5). An error of $\sim 0.2 \mathrm{~m} \mathrm{~s}^{-1}$ in the imbalance between the ebb and flood flow speeds was calculated using (2), resulting from $0.15 \mathrm{~m} \mathrm{~s}^{-1}$ errors in each of the ebb and flood flow speeds. The repeat surveys during the turn of the tide clearly showed how the core of the tidal current shifted around the Inner Sound. As flood turned to ebb or vice versa, the core is displaced.

\section{4) Cross currents}

In addition to the misalignment of the strong flow described above, it is possible for there to be anomalous current directions of moderate strength at the turn of the tide. This can be a function of the "tidal ellipse." Alternatively, if an eddy is formed, then there will be significant cross currents on two sides of that eddy. No such eddies were predicted in the Inner Sound by ORKM (though they are elsewhere), but we found evidence of a transient eddy to the south of Stroma 
near the center of $\mathrm{c} 1, \mathrm{c} 2, \mathrm{c} 3$, and $\mathrm{c} 4$, around $\sim\left(58^{\circ} 39^{\prime} 30^{\prime \prime} \mathrm{N}\right.$, $\left.3^{\circ} 6^{\prime} 30^{\prime \prime} \mathrm{W}\right)$, and just southwest of $\mathrm{c} 2$, around $\sim\left(58^{\circ} 39^{\prime} 30^{\prime \prime} \mathrm{N}\right.$, $\left.3^{\circ} 6^{\prime} 45^{\prime \prime} \mathrm{W}\right)$. The errors in the obtained flow direction at a chosen location and time during the turn of the tide were big, being on the order of tens of degrees, but the presence of an eddy is a robust result of the surveys.

\section{5) VERTICAL SHEAR}

Vertical shear was a major consideration in the planning stages and is known to be a problem elsewhere, but thus far we have not uncovered evidence of strong vertical shears in the upper waters of the Inner Sound. We have routinely analyzed current data at 5,11 , and $15 \mathrm{~m}$ and found that the currents behave similarly at all three depths, as reported for 29 April [section 3b]. The average vertical shears over these depths during the other surveys were generally smaller than those found during 29 April, being closer to 0.01 than to $0.02 \mathrm{~s}^{-1}$. There does not appear to be strong vertical shear associated with the turn of the tide. There are concerns about phenomena nearer the bottom, however, as described in the following paragraph.

\section{6) ADCP RETRIEVAL ERRORS}

ADCP retrieval errors in the lower bins including bin $6(15 \mathrm{~m})$ were encountered repeatedly near and below the line c1-c2, near $58^{\circ} 39^{\prime} 40^{\prime \prime} \mathrm{N}$ latitude, between $3^{\circ} 6^{\prime} 34^{\prime \prime}$ and $3^{\circ} 7^{\prime} 10^{\prime \prime} \mathrm{W}$ longitude. The frequency of these errors increased with depth. The echo from the bottom routinely interferes with the lowest ADCP bins, depending on bottom type, but a relation with bottom depth was not obvious. The errors could not be attributed to the turning of the vessel, as many turns were performed without ADCP errors, and errors occurred on straight transects also. A side-scan sonar survey, using a Starfish $450 \mathrm{~F}$ sonar on a compressed high intensity radar pulse (CHIRP) signal with a nominal frequency of $350 \mathrm{kHz}$, did not reveal objects such as an underwater kelp forest (Salter 2009, his Fig. 1) that could have disturbed the ADCP's acoustic return signal. Other causes we could think of are increased turbulence or suspended sediment. The errors appeared to occur over a bank of accumulated sand, deposited by the currents (Easton et al. 2011). Either way, the current retrieval errors suggest that this location is best avoided when selecting a tidal energy site, because suspended material and turbulence may damage underwater turbines.

\section{e. Selection of most promising sites}

Current speeds over $4 \mathrm{~m} \mathrm{~s}^{-1}$ were measured in the Inner Sound, but the locations where these strong flows were measured were not necessarily the optimal sites for tidal stream turbines. The characteristics discussed above need to be considered in proposing possible test sites. The western part of the Inner Sound (longitude $>$ $3^{\circ} 7^{\prime} 30^{\prime \prime} \mathrm{W}$ ) was dismissed fairly early because of the "misalignment" and wave climate. The easternmost area of the sound (longitude $<3^{\circ} 6^{\prime} 30^{\prime \prime} \mathrm{W}$ ) was also ruled out early primarily on the grounds of low resources. Slightly west of this location initially appeared more promising, however further issues arose later. The most important of these was "asymmetry." It is difficult to be precise, but it is unlikely that there is sufficient overlap of suitably fast ebb and flood streams, west of $3^{\circ} 7^{\prime} \mathrm{W}$ and north of $58^{\circ} 39^{\prime} 40^{\prime \prime} \mathrm{N}$, and east of $3^{\circ} 7^{\prime} 30^{\prime \prime} \mathrm{W}$ and north of $58^{\circ} 39^{\prime} 39^{\prime \prime} \mathrm{N}$. ADCP recording errors over a shallow bank make this an uncertain region. South of $58^{\circ} 39^{\prime} 30^{\prime \prime} \mathrm{N}$, the ebb flow was too weak.

We select "site A" at $\left(58^{\circ} 39^{\prime} 35^{\prime \prime} \mathrm{N}, 3^{\circ} 6^{\prime} 40^{\prime \prime} \mathrm{W}\right)$ (Fig. 2) as the most easterly location where a suitable overlap of ebb and flood streams is probable. The measured current speed interpolated to location A ranged between 0.1 and $2.7 \mathrm{~m} \mathrm{~s}^{-1}$, and was $1.3 \mathrm{~m} \mathrm{~s}^{-1}$ on average. Site A should be close to the center of any transient eddy generated at the turn of the tide, thus reducing the incidence of cross currents. The derived vertical shear between 5 - and $11-\mathrm{m}$ depth changed from 0.024 to $-0.008 \mathrm{~s}^{-1}$ and between 11- and 15-m depth from -0.04 to $0.007 \mathrm{~s}^{-1}$ as the survey progressed during 29 April, illustrating the variation in shear during a turning tide. Slightly farther west is more promising in many respects, though wave climate will inevitably be more severe and there may be cross currents associated with the transient eddies. There should be considerable benefits of the greater overlap in the ebb and flood streams, while the ebb and flood flow misalignment and imbalance are reasonably small for latitudes below $58^{\circ} 39^{\prime} 40^{\prime \prime} \mathrm{N}$. We select "site B" at $\left(58^{\circ} 39^{\prime} 35^{\prime \prime} \mathrm{N}, 3^{\circ} 7^{\prime} 30^{\prime \prime} \mathrm{W}\right)$ (Fig. 2), where current speeds were measured between 0.2 and $3.1 \mathrm{~m} \mathrm{~s}^{-1}$, being $1.5 \mathrm{~m} \mathrm{~s}^{-1}$ on average. At site $\mathrm{B}$, the vertical shear between 5- and 11-m depth was calculated to change from -0.022 to $0.007 \mathrm{~s}^{-1}$ and between 11- and $15-\mathrm{m}$ depth from -0.027 to $0.009 \mathrm{~s}^{-1}$ and back to $-0.003 \mathrm{~s}^{-1}$ during the 29 April survey, indicating the sensitivity of vertical shear to location.

We did not survey during peak spring tides, so maximum currents at both sites are most likely stronger. We estimated how much stronger by regressing the ADCP-derived current speeds at site $\mathrm{A}\left(m_{\mathrm{ADCP}}\right)$ against ORKM current speeds at grid point $\mathrm{c} 2\left(m_{\mathrm{c} 2}\right)$, and doing the same for site $\mathrm{B}$ and grid point $\mathrm{c} 1$. For site $\mathrm{A}$ we retrieved $m_{\mathrm{ADCP}}=0.93 m_{\mathrm{c} 2}\left(R^{2}=0.82\right)$, and for site $B m_{\mathrm{ADCP}}=m_{\mathrm{c} 1}+0.22\left(R^{2}=0.83\right)$. The ORKM-predicted spring tide currents for respective grid points $\mathrm{c} 1$ and $\mathrm{c} 2$ of 3.26 and $3.49 \mathrm{~m} \mathrm{~s}^{-1}$ therefore implied a maximum current 
of $3.3 \mathrm{~m} \mathrm{~s}^{-1}$ at site A and of $3.5 \mathrm{~m} \mathrm{~s}^{-1}$ at site B. The current speed at site B was expected to reach higher values, but analysis of the measurements showed a larger misalignment for site B than for site A. Interpolation of the ebb flow direction to the sites' locations gave $\sim 255^{\circ}$ for both, while the direction of the flood flow gave $84^{\circ}$ for site $\mathrm{A}$ and $100^{\circ}$ for site $\mathrm{B}$. The ORKM predicts that these angles will not be different for spring peak tides. The estimated misalignment between ebb and flood is only $9^{\circ}$ at site $\mathrm{A}$, but $25^{\circ}$ at site $\mathrm{B}$, therefore site $\mathrm{A}$ is preferable in this regard.

Sites A and B are located in the $\sim 31$-m-deep channel in the Inner Sound. Note that these two sites are either side of a "Spoil Ground" marked on the Admiralty chart. However, a side-scan sonar survey did not reveal features that were large enough to be obvious to the eye (Easton et al. 2011). The seabed at sites A and B is tentatively identified as bare rock where sand was completely removed by the tidal stream, which may be suitable for some designs of foundation. Based on our findings, we propose further investigation of these sites.

\section{Conclusions}

Underway ADCP measurements can be used to characterize a tidal energy site. This is particularly useful in harsh wave and current environments, such as in the Inner Sound, where deploying and retrieving longterm bottom-mounted ADCPs can be problematic. The vessel surveys principally yield spatial variations of the tidal currents. A hydrodynamic model can be applied to estimate tidal changes and interpolate the transect data to a fixed time, thereby calculating virtual "snapshots" of the flow. Models and survey data can also be combined to estimate the velocity at peak spring tidal flow (thereby eliminating biases both from the timing of the original surveys and the inadequacy of the model). Our model was ORKM of POLPRED, but any hydrodynamic model that adequately describes the phasing and broad features of the flow can be applied. Although ORKM predictions generally agreed with our measurements, its spatial resolution (and that of other numerical models) was not high enough to assess the smaller-scale phenomena such as eddies, cross currents, and the narrowness of the tidal streams that we observed with the ADCP. These features, together with misalignment and displacement between ebb and flood flows, are essential when assessing a tidal energy site.

Acknowledgments. The authors would like to acknowledge the skill and local knowledge of skipper William Simpson and his help during the fieldwork surveys. We acknowledge the support of the National
Centre for Earth Observation, a NERC Collaborative Centre, and also the Scottish Funding Council (SFC), Highlands and Islands Enterprise (HIE), and UHI through the "AMRECS" program. We acknowledge also the support of HIE, SFC, and the European Regional Development Fund through the Supergen Plus and MaREE Programs. Data were computed using POLPRED software and the Orkney Model developed by the National Oceanography Centre.

\section{REFERENCES}

Bell, C., and L. Carlin, 1998: Generation of UK tidal stream atlases from regularly gridded hydrodynamic modelled data. J. Navig., 51, 73-78.

Bryden, I. G., S. J. Couch, A. Owen, and G. Melville, 2007: Tidal current resource assessment. Proc. Inst. Mech. Eng., 221, 125-135.

Candela, J., R. C. Beardsley, and R. Limeburner, 1992: Separation of tidal and subtidal currents in ship-mounted acoustic Doppler current profiler observations. J. Geophys. Res., 97, 769788.

Carbon Trust, 2011: Accelerating marine energy. [Available online at http://www.carbontrust.com/media/5675/ctc797.pdf.]

Davies, A. M., S. C. M. Kwong, and J. C. Lee, 2001: A detailed comparison of a range of three-dimensional models of the $\mathrm{M}_{2}$ tide in the Faeroe-Shetland Channel and northern North Sea. J. Phys. Oceanogr., 31, 1747-1763.

Easton, M. C., A. Harendza, D. K. Woolf, and A. Jackson, 2011: Characterisation of a tidal energy site: Hydrodynamics and seabed structure. Proc. Ninth European Wave and Tidal Energy Conf., Southampton, United Kingdom, No. 122, $10 \mathrm{pp}$

Epler, J., B. Polagye, and J. Thomson, 2010: Shipboard acoustic Doppler current profiler surveys to assess tidal current resources. Proc. OCEANS, Seattle, WA, MTS/IEEE, 1-10, doi:10.1109/OCEANS.2010.5664387.

Fong, D. A., and S. A. Monismith, 2004: Evaluation of the accuracy of a ship-mounted, bottom-tracking ADCP in a near-shore coastal flow. J. Atmos. Oceanic Technol., 21, 1121-1128.

Foreman, M. G. G., and H. J. Freeland, 1991: A comparison of techniques for tide removal from ship-mounted acoustic Doppler measurements along the southwest coast of Vancouver Island. J. Geophys. Res., 96, 17 007-17 021.

Garrett, C., and P. Cummins, 2005: The power potential of tidal currents in channels. Proc. Roy. Soc., A461, 2563-2572.

Geyer, R., and R. Signell, 1990: Measurements of tidal flow around a headland with a shipboard acoustic Doppler current profiler. J. Geophys. Res., 95 (C3), 3189-3197.

Goddijn-Murphy, L. M., and D. K. Woolf, 2009: Advantages of high resolution mapping of tidal currents in the Pentland Firth, using underway ADCP measurements. Proc. Seventh ADCPs in Action Users' Conf., San Diego, CA, Teledyne RD Instruments, CD-ROM.

Gooch, S., J. Thomson, B. Polagye, and D. Meggitt, 2009: Site characterization for tidal power. Proc. OCEANS on Marine Technology for Our Future: Global and Local Challenges, Biloxi, MS, MTS/IEEE, 1-10. [Available online at http://depts. washington.edu/nnmrec/docs/20090820_GoochS_conf_Site Characterization.pdf.] 
Legrand, C., 2009: Assessment of tidal energy resource. Black \&Veatch Ltd., European Marine Energy Centre, 51 pp.

MacKay, D. J. C., 2009: Sustainable Energy - Without the Hot Air. UIT Cambridge, 366 pp. [Available online at http://www. withouthotair.com.]

Münchow, A., 2000: Detiding three-dimensional velocity survey data in coastal waters. J. Atmos. Oceanic Technol., 17, 736748.

Owen, A., and I. G. Bryden, 2007: Energy extraction implications of structurally significant velocity variation in tidal currents. Proc. OCEANS 2007 - Europe, Aberdeen, Scotland, IEEE/ OES, 1-5, doi:10.1109/OCEANSE.2007.4302409.

Proudman Oceanographic Laboratory, 2007: POLPRED. 2, Proudman Oceanographic Laboratory.

Salter, S. H., 2009: Correcting the Under-estimate of the TidalStream Resource of the Pentland Firth. Proc. Eighth European Wave and Tidal Energy Conf., Uppsala, Sweden. [Available online at http://www.see.ed.ac.uk/ shs/Tidal\%20today/Correcting $\% 20$ the \%20underestimate.pdf.]

— , and J. R. M. Taylor, 2007: Vertical-axis tidal-current generators and the Pentland Firth. Proc. Inst. Mech. Eng., Part A, 221, 181-199.

Sankaran Iyer, A., S. J. Couch, G. P. Harrison, and A. R. Wallace, 2009: Analysis and comparison of tidal datasets. Proc. Eighth European Wave and Tidal Energy Conf., Uppsala, Sweden, 228-236. [Available online at http://www.see.ed.ac.uk/ shs/
Wave \%20Energy/EWTEC\%202009/EWTEC\%202009\%20 (D)/papers/196.pdf.]

Simpson, J. H., E. G. Mitchelson-Jacob, and A. E. Hill, 1990: Flow structure in a channel from an acoustic Doppler current profiler. Cont. Shelf Res., 10, 589-603.

Taylor, J. R. 1982: An Introduction to Error Analysis. University Science Books, 270 pp.

United Kingdom Hydrographic Office, 1986: Tidal Stream Atlas: Orkney and Shetland Islands. 4th ed. Great Britain Hydrographic Department, NP 209, 42 pp.

- 2009: Chart 2162, Pentland Firth and Approaches. Admiralty Charts and Publications.

Vazquez, H. J., J. Gomez-Valdez, and M. Ortiz, 2011: Detiding shipboard ADCP data in eastern boundary current. J. Atmos. Oceanic Technol., 28, 94-103.

Vennell, R., 1994: Acoustic Doppler Current Profiler measurements of tidal phase and amplitude in Cook Strait, New Zealand. Cont. Shelf Res., 14, 353-364.

— , 2006: ADCP measurements of momentum balance and dynamic topography in a constricted tidal channel. J. Phys. Oceanogr., 36, 177-188.

- 2011: Estimating the power potential of tidal currents and the impact of power extraction on flow speeds. Renewable Energy, 36, 3558-3565.

Venugopal, V., and Coauthors, 2011: Wave and tidal resource characterisation. EquiMar Rep., Deliverable D2.2, 79 pp. 